\title{
Bidirectional Partial Power Converter Interface for Energy Storage Systems to Provide Peak Shaving in Grid-Tied PV Plants
}

\author{
Nicolás Müller $_{1,2}$, Samir Kouro ${ }_{1}$, Pericle Zanchetta 2 and Patrick Wheeler 2 \\ ${ }_{1}$ Departament of Electronic Engineering, Universidad Técnica Federico Santa María, Valparaíso, Chile \\ ${ }_{2}$ Department of Electrical and Electronic Engineering, University of Nottingham, Nottingham, United Kingdom \\ Email: nicolas.mullerpollmann@ nottingham.ac.uk
}

\begin{abstract}
The ever growing participation of modern renewable resources in electric markets has shaken the paradigm of generation-demand constant match. Most modern renewables add intermittent behaviour and high variability to electric markets, forcing other renewables and themselves to perform power curtailment and/or having extra generating units connected to the network to compensate power, voltage and frequency variations. In order to handle this scenario, Energy Storage Systems (ESSs) have risen as enabling technologies capable to provide backup energy to compensate power, voltage and frequency fluctuations and, at the same time, offer additional benefits as ancillary services, peak shaving, load shifting, base load generation, etc. This paper presents a novel bidirectional Partial Power Converter (PPC), as an interface between a Battery ESS (BESS) and a gridtied Photovoltaic (PV) plant. To obtain a better understanding of the converter, its mathematical model is presented and its operation modes are explained. The main purpose of this configuration is to provide peak shaving capability to a grid-tied PV plant, while providing a high efficiency BESS. Simulation results show the operation of the full system (grid-tied PV plant and BESS), performing peak shaving under a step-down and up in solar irradiation.
\end{abstract}

\section{INTRODUCTION}

Wind and PV energy have been at the forefront of renewables integration [1]. During the last decades electric markets have experience an immense growth in participation of (traditional and modern) renewable resources, where modern renewables have reached an impressive $10.2 \%$ [2]. This has been mostly motivated by government politics, environmental concerns and fossil fuel depletion [3].

High variability and intermittency of modern renewables have set a virtual limit to renewables participation share in electric markets, since highly variable systems require back-up energy generation [4]-[6]. Nowadays, the mainstream solution to deal with generation-demand mismatches is to have spinning-reserves [5], i.e. sets of back up fast-response costly fossil fuel based generating systems, which must be kept operating idle or at low power level.

ESSs have been vastly researched as an alternative to deal with generation-demand mismatch and provide additional services [6]-[10]. In [6], the addition of ESSs to Wind farms in order to perform peak shaving is analysed. Where an ESS sizing strategy based on Homogeneous Markov Chain, considering wind-storage reliability and increasing the income, is proposed. In [7], the addition of BESS to perform peak shaving in a grid-tied network composed of several loads and PV generation is proposed. The sizing of the BESS considers different pricing strategies, probabilistic neural network forecasting of the behaviour of the load and PV generation. In [8], [9], the addition of super capacitor based ESS is considered to perform global maximum power point tracking in a central inverter PV plant, while complying grid code restrictions on maximum power variation per minute. The addition of a BESS to an islanded wind-diesel-loads power sysatem is analysed in [10], where the BESS provides peak shaving and frequency regulation capabilities.

A paramount part of adding ESSs to a system is choosing the proper Energy Storage Device (ESD) for the application among several different technologies, namely Pumped Hydro Storage, Compressed Air Energy Storage, Flywheel, Fuel Cell, Rechargeable Batteries, Super Capacitor, etc. There have been some studies comparing ESDs features, for instance, in [11] price, energy density, power density, specific power, specific energy, discharge/charge rate, life cycle, depth of discharge, lifespan, energy conversion efficiency, daily self-discharge rate, and ramp time of several ESDs, to provide uninterruptible power supply to data centres, are presented. A deeper comparison of ESDs is presented in [12], where several ESDs are numerically analysed presenting their specific energy, energy density, specific power, power density, efficiency, lifespan, life cycle, life cycle, daily self-discharge rate and scale, cost.

Efficiency is a topic of great importance when analysing power systems and even more when analysing ESDs, since its bidirectional power flow nature incurs in losses during both energy conversion processes (storing and releasing energy). In order to quantify those losses, table I summarises the energy conversion efficiency and daily self-discharge rate of several ESDs shown in [12].

To assess the overall efficiency of ESSs, not only the efficiency of ESDs must be considered, but also the efficiency of the interfacing power converter. Partial Power Converters (PPCs) have emerge as a higher efficiency alternative to traditional DC-DC Full Power Converters (FPCs), in the former only a part of the full system power is processed by the converter, reducing its size and losses compared to FPCs [13]. PPCs have been proposed for a broad variety of unidirectional 
TABLE I

ESD ENERGY CONVERSION EFFICIENCY AND DAILY SELF-DISCHARGE [12]

\begin{tabular}{lrr} 
ESS & Efficiency & Daily self-discharge \\
\hline \hline Lead-acid & $63-90 \%$ & $0.033-1.10 \%$ \\
Lithium-ion & $70-100 \%$ & $0.03-0.33 \%$ \\
Super capacitor & $65-99 \%$ & $0.46-40 \%$ \\
Flywheel & $70-96 \%$ & $24-100 \%$ \\
Pumped Hydro. & $65-87 \%$ & $0 \%$ \\
Compressed Air. & $57-89 \%$ & $0 \%$
\end{tabular}

power flow applications, such as PV power plants [13]-[15], long LED arrays [16] and electric vehicle fast charging stations [17].

This work proposes a novel bidirectional partial power converter topology, as an interface to connect a ESD to a grid-tied PV plant, in order to provide peak shaving capability. Lithium-ion batteries were chosen as the ESD to be applied, since they present the highest efficiency range and the lowest daily self-discharge rate (according to [12]).

This paper is organised as follows: section II presents the proposed configuration, its models, Partial Power Converters equations and BESS sizing. The control scheme for the system is described in section III, the simulation results are explained in section IV and finally section $\mathrm{V}$ provides the conclusions of the work.

\section{CONFIGURATION \& MATHEMATICAL MODELS}

The proposed configuration is shown in Fig. 1, where a BESS is connected to the dc-link of a central inverter PV plant. The battery pack is interfaced, to the dc-link of the central inverter configuration, through 5 interleaved PPCs. Each PPC is formed by 8 semiconductors (MOSFETs), a transformer and an inductance, connected as shown in the figure. The central inverter configuration is composed by an array of several PV modules and a single 2 Level Voltage Source Inverter $(2 L V S I)$ connected to the grid.

The mathematical model of PPC $j(j=\{1, \ldots, 5\})$ is described by equations (1) to (6). The first 3 equations correspond to voltage dynamics, namely voltage across the inductance $L\left(v_{L j}\right)$, voltage across the top winding and its semiconductors $\left(v_{f b p j}\right)$ and voltage in the bottom winding and its semiconductors $\left(v_{f b s j}\right)$. The latter 3 equations correspond to the current dynamics of PPC $j$, where $i_{x j}, i_{b p j}$ and $i_{p p c j}$ correspond respectively to the current through inductance $L$, the bypass current and partial power converter current.

The variables $m_{j}, v_{x}$ and $v_{p v}$ represent respectively the modulation index of PPC $j\left(m_{j} \in[0,1]\right)$, the voltage in the terminals of the battery pack and the voltage across the dclink. The parameters $n_{1}$ and $n_{2}$ correspond respectively to the number of turns in the primary (Fig. 1, top winding) and secondary (Fig. 1, bottom winding) of the transformer.

$$
\begin{gathered}
v_{L j}=\left(\frac{n_{2}}{n_{1}+n_{2}}\right) \cdot v_{p v} \cdot m_{j}-v_{x} \\
v_{f b p j}=\left(\frac{n_{1}}{n_{1}+n_{2}}\right) \cdot v_{p v} \cdot m_{j} \\
v_{f b s j}=\left(\frac{n_{2}}{n_{1}+n_{2}}\right) \cdot v_{p v} \cdot m_{j} \\
i_{x j}=\frac{1}{s \cdot L}\left(\left(\frac{n_{2}}{n_{1}+n_{2}}\right) \cdot v_{p v} \cdot m_{j}-v_{x}\right) \\
i_{b p j}=\left(\frac{n_{2}}{n_{1}+n_{2}}\right) \cdot m_{j} \cdot i_{x j} \\
i_{p p c j}=\left(\frac{n_{1}}{n_{1}+n_{2}}\right) \cdot m_{j} \cdot i_{x j}
\end{gathered}
$$

In order to increase the equivalent switching frequency and reduce the current ripple from and towards the battery pack and dc-link, 5 PPCs are interleaved and their PWM carriers are shifted in $\phi=2 \pi / n$, where $n$ is the amount of interleaved PPCs $(\phi=2 \pi / 5$ in this case).

The mathematical model of the $2 L V S I$ grid currents in $d q$ rotational reference frame $\left(i_{g d}\right.$ and $\left.i_{g q}\right)$, in Laplace domain, is shown in equations (7) and (8). Where $L_{g}, R_{g}, \omega, v_{r d}$, $v_{r q}, v_{g d}$ and $v_{g q}$ correspond respectively to the inductance and resistance of the filter, grid angular frequency, inverter voltages in $d q$ rotational axes and grid voltages in $d q$ rotational reference frame.

$$
\begin{aligned}
& i_{g d}=\frac{1}{L_{g} \cdot s+R_{g}}\left(v_{r d}+L_{g} \cdot \omega \cdot i_{g q}-v_{g d}\right) \\
& i_{g q}=\frac{1}{L_{g} \cdot s+R_{g}}\left(v_{r q}-L_{g} \cdot \omega \cdot i_{g d}-v_{g q}\right)
\end{aligned}
$$

The mathematical model of the voltage across the dc-link capacitor $C_{p v}\left(v_{p v}\right)$ is shown in equation (9). Where $i_{p v}, i_{b p}$, $m_{u}, m_{v}, m_{w}, i_{g u}, i_{g v}, i_{g w}$ correspond to the PV plant output current, total bypass current (through all PPCs), modulation indexes per inverter phase and grid currents.

$$
v_{p v}=\frac{1}{s \cdot C_{p v}}\left(i_{p v}+i_{b p}-m_{u} \cdot i_{g u}-m_{v} \cdot i_{g v}-m_{w} \cdot i_{g w}\right)
$$

\section{A. Partial Power Converters}

In order for a power converter to be considered a PPC, the power processed by the converter must be lower than the input power. This relationship is called partial power ratio $\left(k_{p r}\right)$ and is mathematically represented by the ratio between the PPC processed power and its input power [16]. Therefore, a power converter must comply with $k_{p r}<1$ to be a PPC. Table II summarizes the equations governing the partiality of the proposed bidirectional PPC, for both power flow directions, 


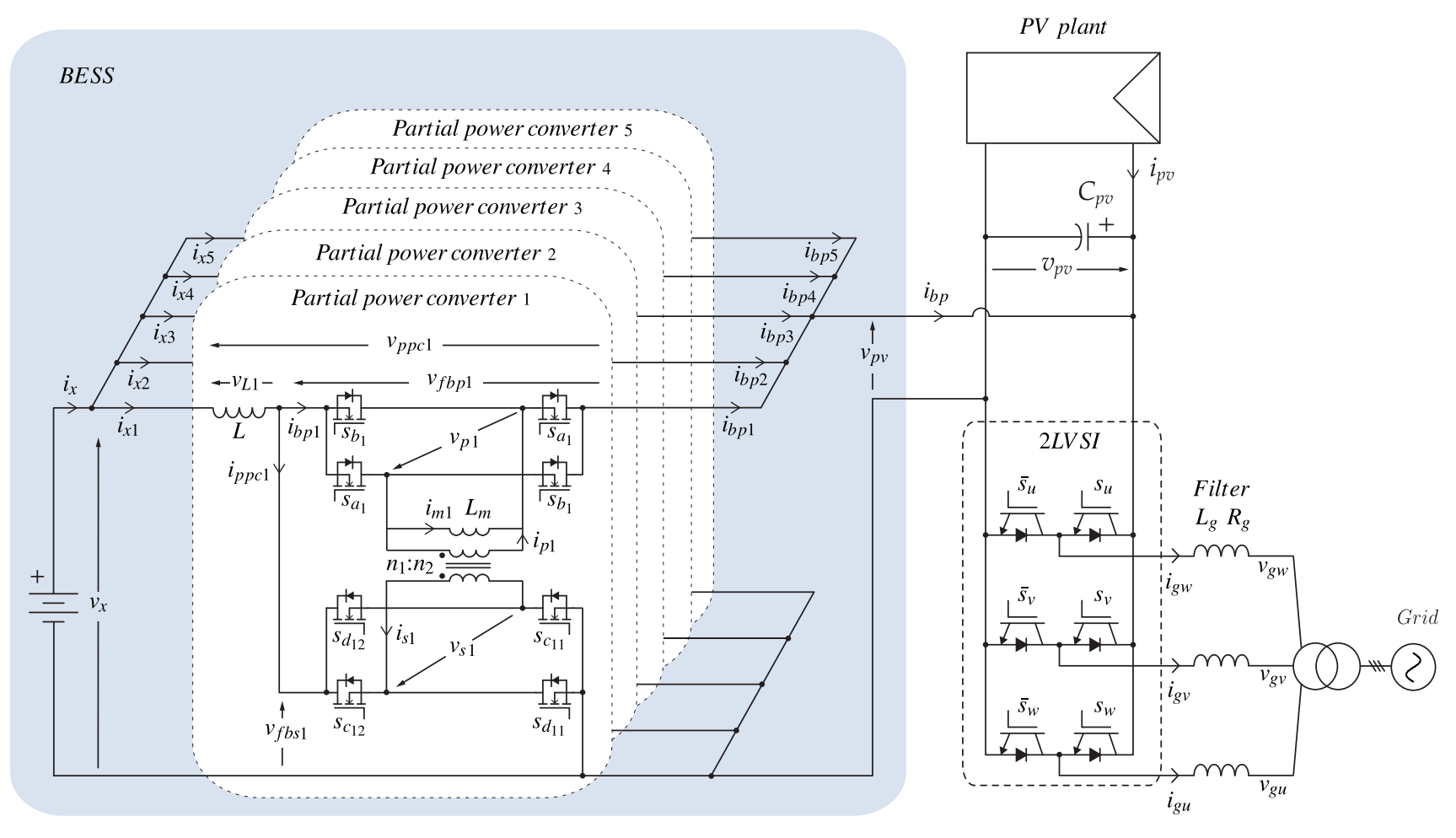

Fig. 1. Proposed configuration

TABLE II

PARTIALITY EQUATIONS

\begin{tabular}{cc}
\hline \hline Power flow towards BESS & Power flow towards dc-link \\
\hline$k_{p r \text { bess }}=\frac{v_{x} \cdot i_{p p c}}{v_{p v} \cdot i_{b p}}$ & $k_{p r d c}=\frac{v_{p v} \cdot i_{b p}}{v_{x} \cdot i_{p p c}}$ \\
$G_{v \text { bess }}=\frac{v_{x}}{v_{p v}}$ & $G_{v d c}=\frac{v_{p v}}{v_{x}}$ \\
$\eta_{\text {bess }}=G_{v \text { bess }}+k_{p r \text { bess }}$ & $\eta_{d c}=\frac{G_{v d c} \cdot k_{p r d c}}{G_{v d c}+k_{p r d c}}$
\end{tabular}

towards the BESS (noted by bess) and towards the dc-link (noted by $d_{c}$ ).

Where $G_{v}$ and $\eta$ correspond respectively to the voltage gain and the efficiency of the converter.

\section{B. Battery Energy Storage Sizing}

A worst case scenario of providing $10 \%$ of the PV plant peak power $(10 \%$ of $1 \mathrm{MW})$ during $t=10$ minutes was considered. This time consideration corresponds to the available time for non-spinning reserves to respond after a contingency, having to be fully operational and able to provide $100 \%$ of its rated power to the electric network [18]. Hence, the BESS must be able to provide:

$$
E_{B E S S}=\frac{10 \% \cdot P_{p v m p p}}{1000 \cdot 60} \cdot t[k W h]=17[k W h]
$$

Where $P_{p v m p p}$ is the maximum power the PV plant can generate and $t$ is the time in minutes.

Due to computational limitations the peak shaving effect provided by the BESS is analysed during short time intervals, nevertheless the battery pack was designed to provide $100 \mathrm{~kW}$ during 10 minutes.

\section{CONTROL}

A conventional Voltage Oriented Control (VOC) scheme, composed by an outer dc-link voltage loop and two inner current loops (direct $i_{g d}$ and quadrature $i_{g q}$ grid currents), is applied to the $2 L V S I$ of the central inverter configuration as shown in Fig. 2. Where $v_{r d}$ and $v_{r q}$ correspond respectively to the direct and quadrature inverter voltages. The dc-link voltage reference $v_{p v}^{*}$ is generated by a traditional Perturb and Observe (P\&O) Maximum Power Point Tracking algorithm.

Figure 3 shows the control scheme applied to each PPC. The leftmost block (PPC bypass current reference), which is explained through Fig. 4, generates the bypass current reference $\left(i_{b p}^{*}\right)$ for each interleaved PPC. A PI controller processes the error between $i_{b p}^{*}$ and the measurement of the bypass current in PPC $j\left(i_{b p j}\right)$, generating the modulation index, which is later passed to the PWM modulation block generating the signals $\tilde{s}_{a j}, \tilde{s}_{b j}, \tilde{s}_{c j 1}, \tilde{s}_{c j 2}, \tilde{s}_{d j 1}$ and $\tilde{s}_{d j 2}$. Later depending on the power flow direction those signals are enabled (or disabled) by multiplying them by a signal named boost or its negated $\overline{\text { boost }}$ generating the gate signals $s_{a j}, s_{b j}, s_{c j 1}, s_{c j 2}, s_{d j 1}$ and $s_{d j 2}$, as shown in Fig. 3. When power flows towards the dclink boost $=1(\overline{\text { boost }}=0)$ the gate signals $s_{a j}$ and $s_{b j}$ are 


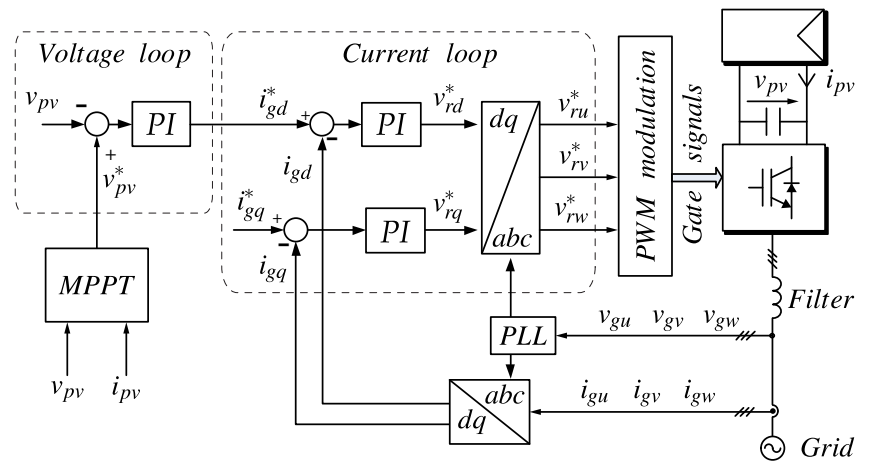

Fig. 2. Inversor control scheme

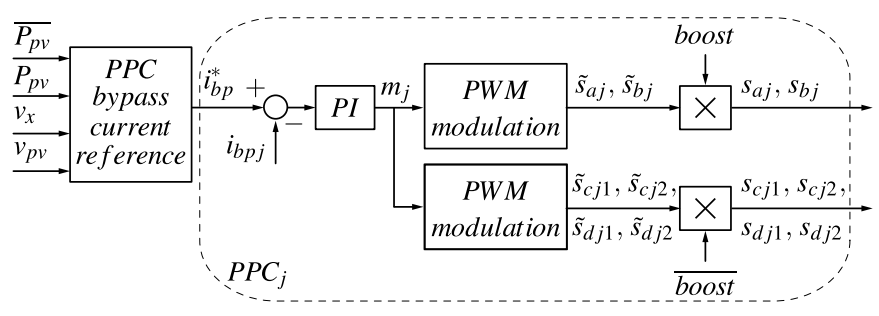

Fig. 3. Bidirectional PPC control scheme

TABLE III

EST CURRENT REFERENCE VALUES

\begin{tabular}{crcrcr}
\hline \hline Symbol & Value & Symbol & Value & Symbol & Value \\
\hline$\hat{i}_{b p}$ & $100 A$ & $i_{b p \gamma}$ & $-4 A$ & $i_{4}$ & $2 A$ \\
$i_{b p \alpha}$ & $4 A$ & $\check{i}_{b p}$ & $-100 A$ & $i_{5}$ & $1 A$ \\
$i_{b p \beta}$ & $-1 A$ & $i_{3}$ & $3 A$ & $i_{6}$ & $-3 A$ \\
\hline
\end{tabular}

modulated, keeping $s_{c j 1}=s_{c j 2}=s_{d j 1}=s_{d j 2}=0$. On the other hand, when the power flows towards the battery pack, boost is $0(\overline{b o o s t}=1)$ and gate signals $s_{c j 1}, s_{c j 2}, s_{d j 1}$ and $s_{d j 2}$ are modulated, while $s_{a j}=s_{b j}=0$.

PPC bypass current reference block (Fig. 3), operates according to the graph shown in Fig. 4. Where $\overline{P_{p v}}, P_{p v}, n$, $v_{p v}, v_{x}, \check{v}_{x}, \hat{v}_{x}$ correspond respectively to the filtered PV plant power, current PV plant power, number of interleaved PPCs, dc-link voltage, BESS current voltage, BESS minimum safety voltage ( $80 \%$ Depth of Discharge) and BESS maximum safety voltage ( $99 \%$ of Maximum battery pack voltage). When the quotient between $\lambda=\left(\overline{P_{p v}}-P_{p v}\right) /\left(n \cdot v_{p v}\right)$ is greater or equal to $i_{3}$ and $\breve{v}_{x}<v_{x}$ the reference $i_{b p}^{*}$ is given according to the purple curve (top right). If $\lambda \geq i_{3}$, but $v_{x}<\check{v}_{x}$, then $i_{b p}^{*}=0$. On the other hand, when $\lambda$ is lower than $i_{4}$ and $v_{x}<\hat{v}_{x}$, the reference is given by the pink curve (bottom left). If $\lambda<i_{4}$ but $\hat{v}_{x}<v_{x}$, then the reference $i_{b p}^{*}$ is 0 . In order to keep BESS voltage $\left(v_{x}\right)$ within a certain range, a charging strategy was added to the bypass current reference generation algorithm, $i_{b p}^{*}=i_{b p \beta}$ when $i_{6} \leq \lambda<i_{5}$ and $v_{x}<\hat{v}_{x}$.

The parameter used in Fig. 4 are shown in table III.

\section{Simulation Results}

The circuital model of the full system was implemented in PLECS.

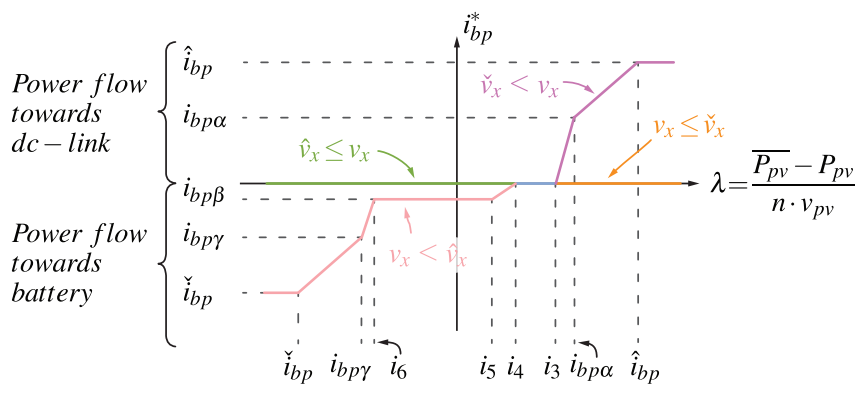

Fig. 4. PPC bypass current reference

TABLE IV

CONFIGURATION PARAMETERS.

\begin{tabular}{|c|c|c|}
\hline \multicolumn{3}{|c|}{ PV power plant (under STC conditions) } \\
\hline Maximum power & $P_{p v m p p}$ & $1 M W$ \\
\hline Open circuit voltage & $v_{p v o c v}$ & $970 \mathrm{~V}$ \\
\hline Short circuit current & $i_{p v s c}$ & $1327 A$ \\
\hline Maximum power point voltage & $v_{p v} m p p$ & $796 \mathrm{~V}$ \\
\hline Maximum power point current & $i_{p v m p p}$ & $1256 A$ \\
\hline Modules connected in series & $N_{s m}$ & 21 \\
\hline Strings connected in parallel & $N_{p s}$ & 140 \\
\hline \multicolumn{3}{|c|}{$\begin{array}{ll}\text { 2LVSI \& Grid } \\
\end{array}$} \\
\hline PV 2LVSI dc-link capacitance & $C_{p v}$ & $4400 \mu F$ \\
\hline PV inverter dc-link voltage & $v_{p v}$ & $740-1000 \mathrm{~V}$ \\
\hline Grid voltage & $v_{a c R M S}$ & $440 V_{L L} R M S$ \\
\hline Grid inductance & $L_{g}$ & $0.25 \mathrm{mH}$ \\
\hline Grid frequency & $f_{g}^{g}$ & $50 \mathrm{~Hz}$ \\
\hline Switching frequency & $f_{s w}$ & $5 \mathrm{kHz}$ \\
\hline \multicolumn{3}{|c|}{ Battery pack } \\
\hline Single cell capacity & $C_{\text {cell }}$ & $6 A h$ \\
\hline Maximum cell discharge rate & $C_{\text {rate out }}$ & $20 C$ \\
\hline Maximum cell charge rate & $C_{\text {rate in }}$ & $19 C$ \\
\hline Number of cells & $N_{\text {cells }}$ & 1211 \\
\hline BESS maximum safety voltage & $\hat{v}_{x}$ & $649 \mathrm{~V}$ \\
\hline BESS minimum safety voltage & $\check{v}_{x}$ & $480 \mathrm{~V}$ \\
\hline \multicolumn{3}{|l|}{$\begin{array}{lc} & \text { PPCs }\end{array}$} \\
\hline PPC inductance & $L$ & $1 m H$ \\
\hline PPC magnetising inductance & $L_{m}$ & $1 \mathrm{mH}$ \\
\hline PPC transformer ratio & $n_{1}: n_{2}$ & $2: 1$ \\
\hline Switching frequency & $f_{b b}$ & $100 \mathrm{kHz}$ \\
\hline Sampling period & $T_{s}$ & $1 \mu s$ \\
\hline
\end{tabular}

Table IV, shows the parameters applied in the simulation. A $1 M W$ PV plant was considered, based on Canadian Solar CS6X-340M-FG PV modules, a tailored battery pack formed by muRata $6 A h \mathrm{LiB}$ battery cells was considered.

In order to validate the configuration two steps in solar irradiation were applied, while keeping temperature constant at $25^{\circ} \mathrm{C}$. The first step consists in a step-down in solar irradiation from 1000 to $700 \mathrm{~W} / \mathrm{m}^{2}$ at $0.5[\mathrm{~s}]$, the second step corresponds to a step-up from 700 to $1000 \mathrm{~W} / \mathrm{m}^{2}$ at $1.3[s]$. The results of the test are shown in the following charts. Fig. 5 shows the solar irradiation and inverter signals, sub-plot (a) shows the solar irradiation $(G)$, sub-plot (b) displays the PV plant output current $\left(i_{p v}\right)$, sub-plot (c) shows the dc-link voltage $\left(v_{p v}\right)$ and its reference $\left(v_{p v}^{*}\right)$, sub-plot (d) shows the grid currents in rotational $\left(i_{g d}\right.$ and $\left.i_{g q}\right)$ and stationary $\left(i_{g u}, i_{g v}\right.$ and $\left.i_{g w}\right)$ reference frame.

The step-down in solar irradiation $(G)$ at $0.5 s$ is reflected in a step-down in PV plant output current $\left(i_{p v}\right)$. The instan- 

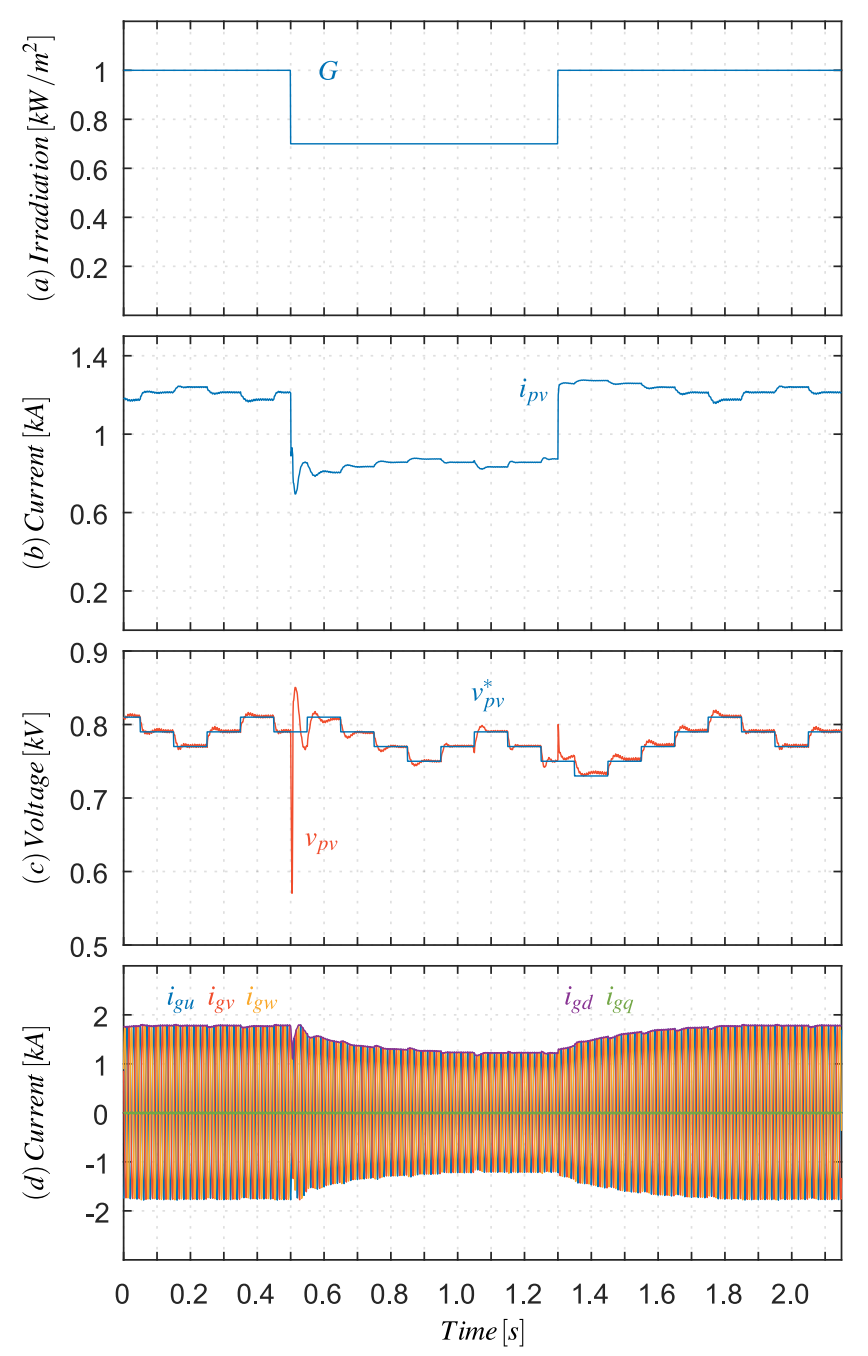

Fig. 5. PV plant and grid side converter signals: (a) Solar irradiation $(G)$, (b) PV plant output current $\left(i_{p v}\right)$, (c) $2 L V S I$ dc-link voltage $\left(v_{p v}\right)$ and its reference $\left(v_{p v}^{*}\right)$, (d) $2 L V S I$ grid currents in stationary $\left(i_{g u}, i_{g v}\right.$ and $\left.i_{g w}\right)$ and rotational $\left(i_{g d}\right.$ and $\left.i_{g q}\right)$ reference frame.

taneous mismatch between $i_{p v}$ and the grid currents $\left(i_{g u}, i_{g v}\right.$ and $\left.i_{g w}\right)$ causes a fast decrease of the dc-link voltage $\left(v_{p v}\right)$ at $t=0.5 \mathrm{~s}$, which is instantaneously corrected by the $2 L V S I$ controller by decreasing the grid currents. The later increase and smooth decrease of grid currents (from 0.5 to $1.2 \mathrm{~s}$ ) is explained by the extra power injected to the dc-link by the BESS.

The step-up in solar irradiation $(G)$ at $1.3 \mathrm{~s}$ generates a step-up in the PV plant output current $\left(i_{p v}\right)$. The instantaneous mismatch between the grid currents and the PV plant output current generates a sudden increase in the dc-link voltage $\left(v_{p v}\right)$, which is corrected by the inverter control scheme by increasing the grid currents. The smooth increase of the grid currents, despite the step-up in $P_{p v}$ (from 1.3 to $2.0 \mathrm{~s}$ ), is due to the power being stored in the BESS.

It must be notice that the $\mathrm{P} \& \mathrm{O}$ algorithm keeps tracking the MPP dc-link voltage, even when the BESS is releasing or storing energy.
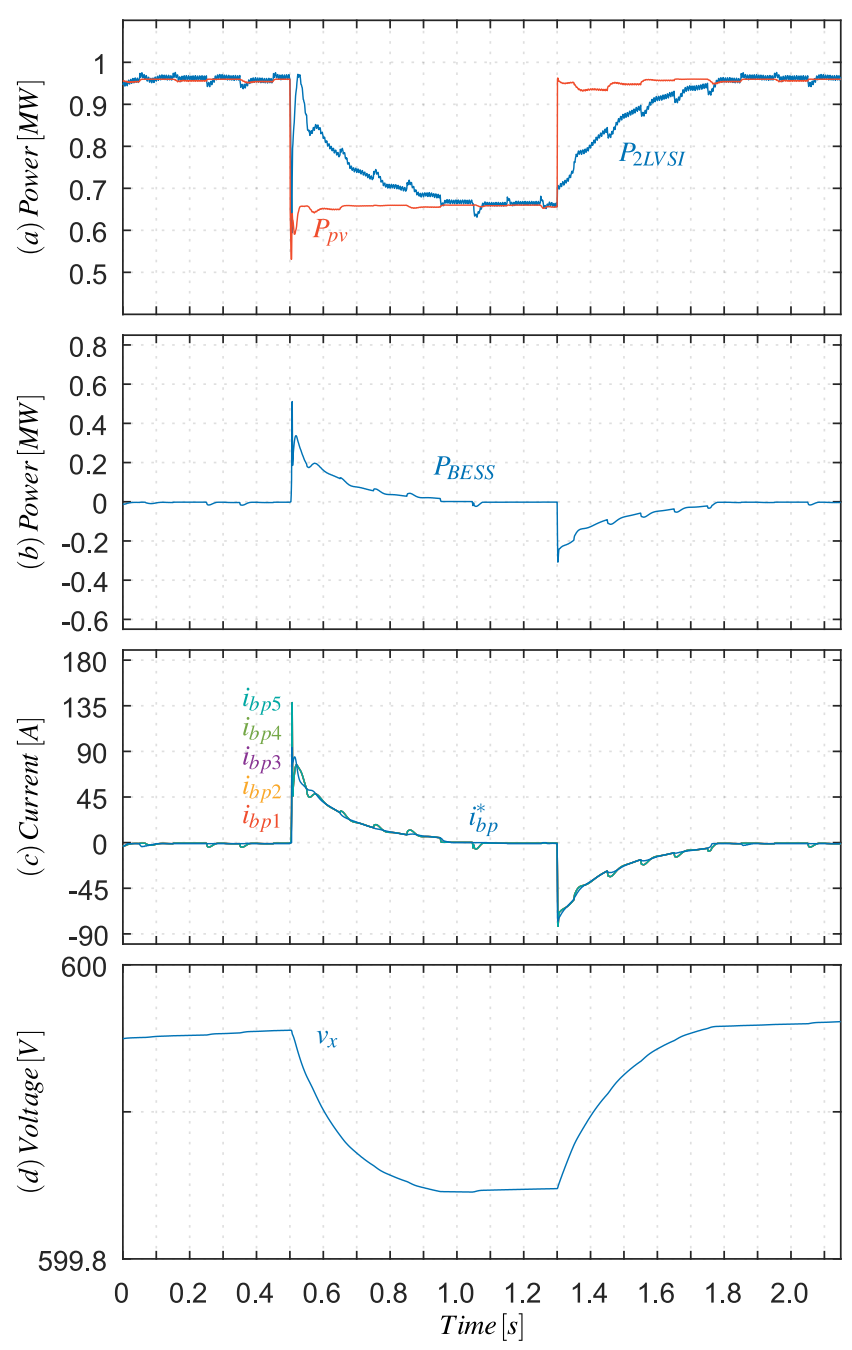

Fig. 6. System power and BESS signals: (a) Power injected to the grid $\left(P_{2 L V S I}\right)$ and power provided by the PV plant $\left(P_{p v}\right)$, (b) Power injected to the dc-link by the BESS $\left(P_{B E S S}\right)$, (c) PPCs bypass currents $\left(i_{b p 1}, i_{b p 2}\right.$, $i_{b p 3}, i_{b p 4}$ and $\left.i_{b p 5}\right)$ and its reference $\left(i_{b p}^{*}\right)$, (d) BESS terminal voltage $\left(v_{x}\right)$.

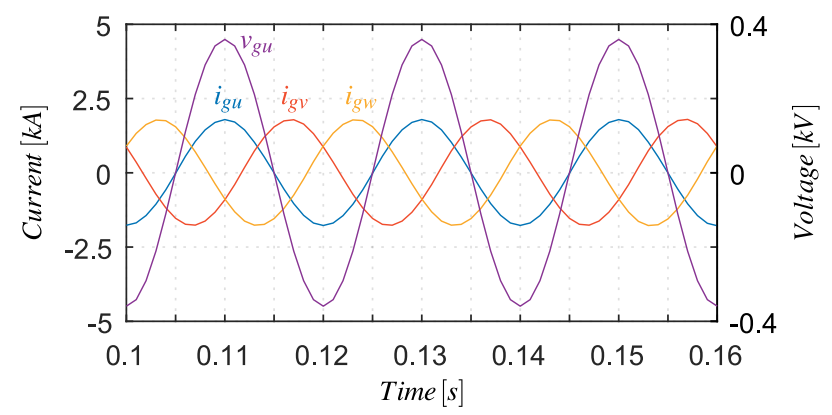

Fig. 7. Zoomed grid signals: grid currents $\left(i_{g u}, i_{g v}\right.$ and $\left.i_{g w}\right)$ and phase $u$ grid voltage $\left(v_{g u}\right)$.

BESS, PV plant output power and $2 L V S I$ output power signals are shown in Fig. 6. Sub-plot (a) shows the PV plant output power $\left(P_{p v}\right)$ and the power injected to the grid by the inverter $\left(P_{2 L V S I}\right)$. The power released (positive) and stored (negative) by the BESS $\left(P_{B E S S}\right)$ is displayed in sub-plot (b). 
Sub-plot (c) shows the bypass currents $\left(i_{b p j}, j=\{1, \ldots, 5\}\right)$ and its reference $\left(i_{b p}^{*}\right)$. The terminal voltage across the battery pack $\left(v_{x}\right)$ is shown in sub-plot (d).

The step-down in solar irradiation at $0.5 \mathrm{~s}$ causes a positive difference between the average $\left(\overline{P_{p v}}\right)$ and the instantaneous $\left(P_{p v}\right)$ PV plant output power (hence $\lambda>0$ ), commanding the BESS to inject current (power) to the dc-link (from 0.5 to $1.2 \mathrm{~s}$ ). The power injected from the BESS mitigates the step-down in full system output power $\left(P_{2 L V S I}\right)$, generating a smooth transition. As the average PV plant output power decreases, the PPCs bypass current reference $\left(i_{b p}^{*}\right)$ decreases proportionally until reaching zero reference. The power drawn from the BESS towards the dc-link is reflected in a decrease of the battery pack terminal voltage $\left(v_{x}\right)$.

The step-up in solar irradiation at $1.3 \mathrm{~s}$ generates a negative difference between $\overline{P_{p v}}$ and $P_{p v}(\lambda<0)$, hence commanding the BESS to take (store) energy from the dc-link, while smoothing the total system output power curve (from 1.3 to $2 s)$. The negative value in BESS power $\left(P_{B E S S}\right)$ represents stored energy. As $P_{B E S S}$ smoothly increases (towards zero) proportionally increases the bypass current reference $\left(i_{b p}^{*}\right)$. The injection of power from the dc-link towards the BESS is reflected as an increase of the battery pack terminal voltage $\left(v_{x}\right)$.

\section{CONCLUSION}

This paper presents a bidirectional PPC as an interface to merge a battery pack to a grid-tied PV plant, in order to provide peak shaving capability. The BESS enables the PV system to store (release) exceeding (lacking) PV power, providing peak shaved power to the grid.

A full description and model of the system were given, providing a deeper understanding on how this bidirectional PPC operates. A tailored control strategy to manage the power flow between the battery pack and dc-link was tested, enabling the full system to inject peak shaved power to the grid. The standard P\&O MPPT algorithm was able to operate normally, even when power was being drawn or injected to the dc-link by the BESS.

The proposed BESS configuration and control scheme were designed to be a plug-in solution for existing grid-tied PV plants, lacking peak shaving capability. Moreover, a small modification in the control strategy will allow BESS to mitigate (avoid) PV plants power curtailment, required by grid operators to compensate grid frequency variations.

As a possible future work the authors propose the possibility to perform peak shaving and short term ancillary services without adding additional energy storage.

\section{ACKNOWLEDGMENT}

The authors gratefully acknowledge the financial support provided by FONDECYT 1171823, AC3E (CONICYT/BASAL/FB0008), SERC Chile (CONICYT/FONDAP/15110019) and CONICYT-PCHA/Doctorado Nacional/2014-21141092.

\section{REFERENCES}

[1] REN21, The First Decade 2004-2014 www.ren21.net. REN21, 2016.

[2] REN21, Renewables 2017 Global Status Report www.ren21.net. REN21, 2017.

[3] I. E. Commission et al., Grid Integration of Large-capacity Renewable Energy Sources and Use of Large-capacity Electrical Energy Storage: White Paper; October 2012. International Electrotechnical Commission, 2012.

[4] J. Widén, N. Carpman, V. Castellucci, D. Lingfors, J. Olauson, F. Remouit, M. Bergkvist, M. Grabbe, and R. Waters, "Variability assessment and forecasting of renewables: A review for solar, wind, wave and tidal resources," Renewable and Sustainable Energy Reviews, vol. 44, pp. 356-375, 2015.

[5] M. N. Hjelmeland, C. T. Larsen, M. Korpås, and A. Helseth, "Provision of rotating reserves from wind power in a hydro-dominated power system," in Probabilistic Methods Applied to Power Systems (PMAPS), 2016 International Conference on. IEEE, 2016, pp. 1-7.

[6] J. Dong, F. Gao, X. Guan, Q. Zhai, and J. Wu, "Storage sizing with peak-shaving policy for wind farm based on cyclic markov chain model," IEEE Transactions on Sustainable Energy, vol. 8, no. 3, pp. 978-989, 2017.

[7] B.-R. Ke, T.-T. Ku, Y.-L. Ke, C.-Y. Chuang, and H.-Z. Chen, "Sizing the battery energy storage system on a university campus with prediction of load and photovoltaic generation," IEEE Transactions on Industry Applications, vol. 52, no. 2, pp. 1136-1147, 2016.

[8] N. Müller, S. Kouro, H. Renaudineau, and P. Wheeler, "Energy storage system for global maximum power point tracking on central inverter pv plants," in Power Electronics Conference (SPEC), IEEE Annual Southern. IEEE, 2016, pp. 1-5.

[9] N. Müller, H. Renaudineau, F. Flores-Bahamonde, S. Kouro, and P. Wheeler, "Ultracapacitor storage enabled global mppt for photovoltaic central inverters," in Industrial Electronics (ISIE), 2017 IEEE 26th International Symposium on. IEEE, 2017, pp. 1046-1051.

[10] R. Sebastián, "Application of a battery energy storage for frequency regulation and peak shaving in a wind diesel power system," IET Generation, Transmission \& Distribution, vol. 10, no. 3, pp. 764-770, 2016.

[11] D. Wang, C. Ren, A. Sivasubramaniam, B. Urgaonkar, and H. Fathy, "Energy storage in datacenters: what, where, and how much?" in $A C M$ SIGMETRICS Performance Evaluation Review, vol. 40, no. 1. ACM, 2012, pp. 187-198.

[12] S. Sabihuddin, A. E. Kiprakis, and M. Mueller, "A numerical and graphical review of energy storage technologies," Energies, vol. 8, no. 1, pp. 172-216, 2014.

[13] J. W. Zapata, H. Renaudineau, S. Kouro, M. A. Perez, and T. A. Meynard, "Partial power dc-dc converter for photovoltaic microinverters," in Industrial Electronics Society, IECON 2016-42nd Annual Conference of the IEEE. IEEE, 2016, pp. 6740-6745.

[14] J. W. Zapata, T. A. Meynard, and S. Kouro, "Partial power dc-dc converter for large-scale photovoltaic systems," in Power Electronics Conference (SPEC), IEEE Annual Southern. IEEE, 2016, pp. 1-6.

[15] A. Morrison, J. W. Zapata, S. Kouro, M. A. Perez, T. A. Meynard, and H. Renaudineau, "Partial power dc-dc converter for photovoltaic twostage string inverters," in Energy Conversion Congress and Exposition (ECCE), 2016 IEEE. IEEE, 2016, pp. 1-6.

[16] J. W. Zapata, T. A. Meynard, and S. Kouro, "Multi-channel partial power dc-dc converter for current balancing of led strings," in Industrial Electronics (ISIE), 2017 IEEE 26th International Symposium on. IEEE, 2017, pp. 775-780.

[17] J. Rojas, H. Renaudineau, S. Kouro, and S. Rivera, "Partial power dcdc converter for electric vehicle fast charging stations," in Industrial Electronics Society, IECON 2013-43rd Annual Conference of the IEEE. IEEE, 2017, pp. -.

[18] A. Chuang and C. Schwaegerl, "Ancillary services for renewable integration," in Integration of Wide-Scale Renewable Resources into the Power Delivery System, 2009 CIGRE/IEEE PES Joint Symposium. IEEE, 2009, pp. 1-1. 